\title{
Extracorporeal selective chloride removal by electrodialysis: an innovative treatment for respiratory and metabolic ACIDOSIS
}

\author{
A Zanella ${ }^{1 *}$, L Caironi ${ }^{2,3}$, P Castagna ${ }^{1}$, M Giani ${ }^{1}$, S Abd El Aziz El Sayed Deab ${ }^{1}$, E Scotti ${ }^{2}$, M Chiodi ${ }^{2}$, F Zadek ${ }^{2}$, \\ S Colombo', D Salerno ${ }^{1}$, L Gattinoni ${ }^{2,4}$, A Pesenti $^{1,5}$
}

From ESICM LIVES 2015

Berlin, Germany. 3-7 October 2015

\section{Introduction}

Acidosis is a frequent disorder among critically ill patients. When patient compensatory responses fail to restore a normal $\mathrm{pH}$, administration of sodium bicarbonate $\left(\mathrm{NaHCO}_{3}\right)$ or renal replacement therapy may be required. Intravenous $\mathrm{NaHCO}_{3}$ increases plasma Strong Ion Difference $\left([\mathrm{SID}]=\left[\mathrm{Na}^{+}\right]+\left[\mathrm{K}^{+}\right]-\left[\mathrm{Cl}^{-}\right]\right)$and $\mathrm{HCO}_{3}{ }^{-}$ concentration by raising $\mathrm{Na}^{+}$concentration. Although effective, this treatment is not devoid of complications, such as hypernatremia, hyperosmolarity and fluid overloading[1]. Selective chloride $\left(\mathrm{Cl}^{-}\right)$removal, by increasing SID in an alternative way, may allow a rapid correction of acidosis without altering plasma osmolality and $\mathrm{Na}^{+}$ concentration.

\section{Objectives}

In an experimental animal model of severe respiratory and metabolic acidosis, we aimed to assess the efficacy of an electrodialytic system, able to selectively remove anions from plasma ultrafiltrate, to normalize $\mathrm{pH}$.

\section{Methods}

Seven sedated and paralyzed healthy swine were connected to a veno-venous extracorporeal circuit including a dialyzer and an electrodialysis unit. Animals underwent 2 randomly-ordered experimental sequences of respiratory and metabolic acidosis, obtained by reducing the respiratory rate or by continuous infusion of lactic acid, respectively, targeting an arterial $\mathrm{pH}$ of $7.15 \pm 0.02$. The electrodialysis treatment was then started to restore baseline $\mathrm{pH}$. Hemodynamics, acid-base equilibrium, and laboratory parameters were recorded.

\section{Results}

An arterial $\mathrm{pCO}_{2}$ of $91 \pm 11 \mathrm{mmHg}$ and a lactate concentration of $13.2 \pm 1.4 \mathrm{mmol} / \mathrm{L}$ were required to achieve the targeted respiratory and metabolic acidosis, respectively. The electrodialysis treatment restored the baseline $\mathrm{pH}$ by reducing plasma $\mathrm{Cl}^{-}$concentration respectively from $105 \pm 4$ to $79 \pm 8 \mathrm{mEq} / \mathrm{L}$ in $306 \pm 54$ min (for respiratory acidosis), and from $105 \pm 3$ to $91 \pm$ $5 \mathrm{mEq} / \mathrm{L}$ in $175 \pm 47 \mathrm{~min}$ (for metabolic acidosis) ( $\mathrm{p}<$ 0.001 for both, see Figure 1). No adverse events ascribable to the treatment were recorded.

\section{Conclusions}

Selective extracorporeal removal of $\mathrm{Cl}^{-}$by electrodialysis is a feasible, rapid and effective in-vivo treatment to completely reverse severe respiratory or metabolic acidosis.

\section{Authors' details}

${ }^{1}$ Università degli Studi di Milano Bicocca, Monza, Italy. ${ }^{2}$ Università degli Studi di Milano, Milano, Italy. ${ }^{3}$ Ospedale Maggiore Policlinico, Milano, Italy.

${ }^{4}$ Fondazione IRCCS Ca' Granda - Ospedale Maggiore Policlinico, Milano, Italy. ${ }^{5}$ Ospedale San Gerardo, Monza, Italy.

\section{Published: 1 October 2015}

\section{Reference}

1. Cooper DJ, Worthley LI: Adverse haemodynamic effects of sodium bicarbonate in metabolic acidosis. Intensive Care Med 1987, 13(6):425-427.

'Università degli Studi di Milano Bicocca, Monza, Italy

Full list of author information is available at the end of the article

(c) 2015 Zanella et al.; This is an Open Access article distributed under the terms of the Creative Commons Attribution License (http:// creativecommons.org/licenses/by/4.0), which permits unrestricted use, distribution, and reproduction in any medium, provided the original work is properly cited. 


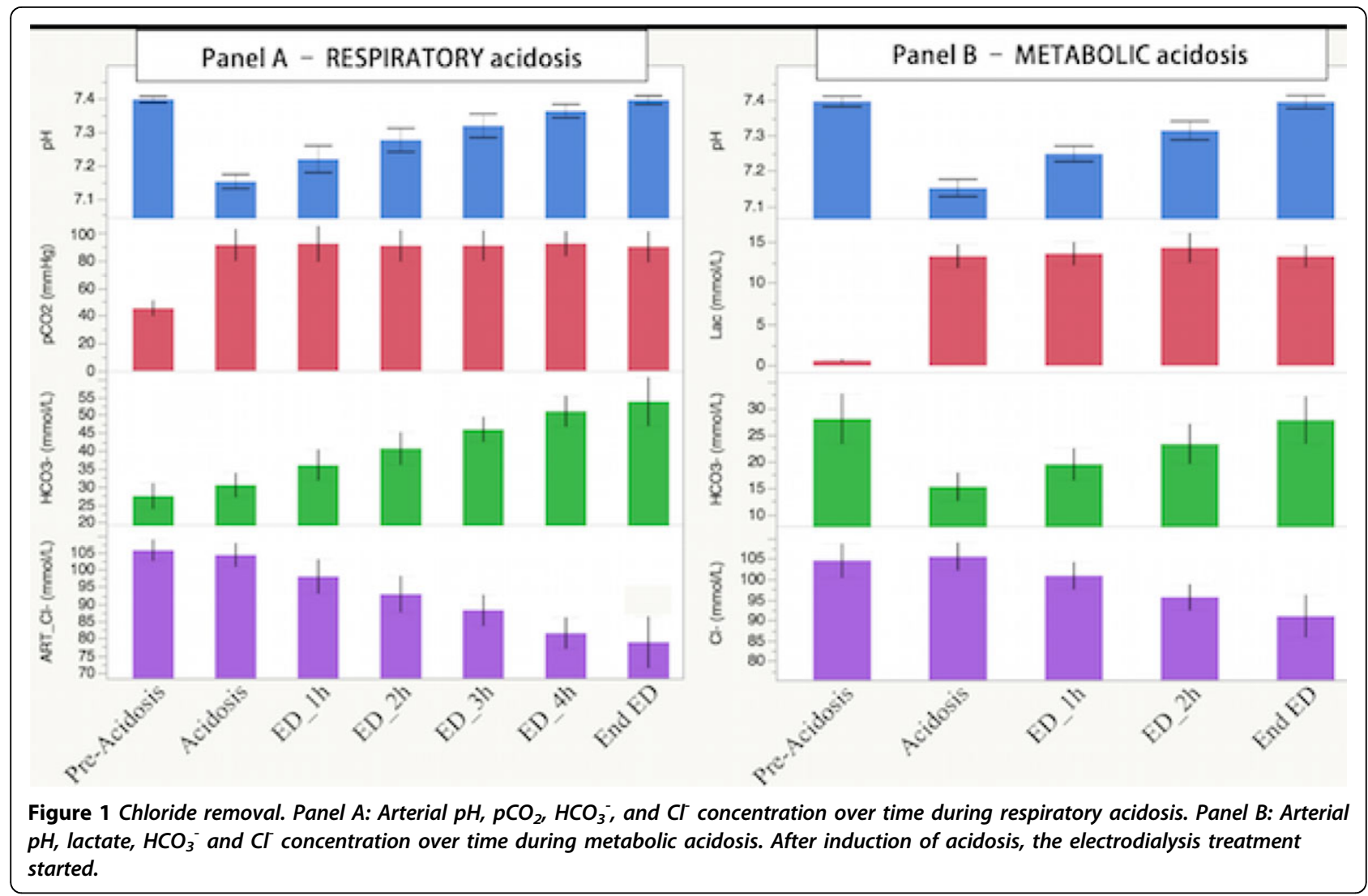

doi:10.1186/2197-425X-3-S1-A502

Cite this article as: Zanella et al.: Extracorporeal selective chloride

removal by electrodialysis: an innovative treatment for respiratory and

metabolic ACIDOSIS. Intensive Care Medicine Experimental 2015 3(Suppl 1):

A502.

Submit your manuscript to a SpringerOpen ${ }^{\circ}$ journal and benefit from:

- Convenient online submission

- Rigorous peer review

- Immediate publication on acceptance

- Open access: articles freely available online

- High visibility within the field

- Retaining the copyright to your article 